\title{
Individual differences in if-then planning: Insights from the development and application of the If-Then Planning Scale (ITPS)
}

\author{
Maik Bieleke ${ }^{a, *}$, Lucas Keller ${ }^{b}$ \\ ${ }^{a}$ Department of Developmental and Educational Psychology, Faculty of Psychology, University of Vienna, Vienna, Austria \\ ${ }^{\mathrm{b}}$ Department of Psychology, University of Konstanz, Konstanz, Germany
}

\section{A R T I C L E I N F O}

\section{Keywords:}

If-then planning

Implementation intentions

Self-regulation

Individual differences

Motivation

\begin{abstract}
A B S T R A T
Making if-then plans is a self-regulation strategy that facilitates goal attainment. An open question is, however, whether there are individual differences in if-then planning. We, therefore, developed and validated the If-Then Planning Scale (ITPS) in three independent studies with more than 2600 participants. The ITPS is conceptually grounded in implementation intention theory, measuring whether individuals identify critical situations (if-part) and plan goal-directed behaviors (then-part) in terms of opportunities and obstacles. We established the psychometric qualities of the ITPS in Studies $1 \mathrm{a}$ and $1 \mathrm{~b}$ and its convergent and discriminant validity in Studies 2 and 3. Applying the ITPS, we showed that if-then planning is associated with the attainment of environmental goals (Studies 1a and 1b), socioeconomic status (Studies 1a, 1b, and 2), and academic achievement (Study 3). Our results demonstrate individual differences in if-then planning that can be efficiently and reliably measured with the ITPS, and reveal systematic associations between these individual differences and goal attainment.
\end{abstract}

\section{Introduction}

People often fail to perform the behaviors necessary for attaining their goals (Sheeran \& Webb, 2016). A self-regulation strategy that can help narrow this intention-behavior gap is making if-then plans (implementation intentions; Gollwitzer, 1999, 2014). If-then planning involves that people specify in advance when, where, and how they will act towards their goals. Meta-analytic evidence suggests that prompting people to engage in if-then planning for a specific goal facilitates its attainment (Gollwitzer \& Sheeran, 2006), with examples ranging from eating behavior (e.g., Adriaanse et al., 2011), physical activity (e.g., Bélanger-Gravel et al., 2013), to addictions (e.g., McWilliams et al., 2019). However, the question of whether there are individual differences in using if-then plans as a self-regulation strategy has received surprisingly little attention (Bieleke, Keller, \& Gollwitzer, n.d.). This is an unfortunate blind spot: Basic research might account for these individual differences when testing the effects of if-then planning. Furthermore, knowing who would benefit the most from a prompt to engage in if-then planning could enable tailored and efficient interventions. And eventually, measures of this individual difference could capture lasting and generalized effects of if-then planning interventions.

It seems intuitive that some people are more likely than others to furnish their goals with if-then plans even without explicit prompts, and that these individuals better attain their goals. This is what one of the earliest studies on if-then planning suggests (Gollwitzer \& Brandstätter, 1997, Study 1) in which about $2 / 3$ of the participants indicated that they had made if-then plans for a specific personal goal, and these participants were more likely to attain their goal than participants who did not make such plans. Previous research also indicates that people with a higher propensity to plan experience higher prosperity and wealth than others (Lynch et al., 2010). Finally, there is evidence that people differ in planning their physical activities (Lippke et al., 2004) and other healthrelated behaviors (Luszczynska \& Schwarzer, 2003), which is predictive of goal attainment.

However, the mentioned studies investigate individual differences in planning for a certain goal (e.g., how to spend one's money; Lynch et al., 2010), making the results difficult to generalize. In contrast, studies that conceive of planning as a general trait (e.g., planfulness; Ludwig et al., 2019; future planning; Prenda \& Lachman, 2001) do not limit their scope to a certain goal. However, they conceive of planning as a subfacet of conscientiousness and cover various aspects unrelated to the selfregulation strategy of if-then planning. These measures are therefore rather broad and cannot tap into crucial aspects of if-then plans according to implementation intention theory (e.g., using an if-then

\footnotetext{
* Corresponding author at: University of Vienna, Universitaetsstrasse 7, 1010 Vienna, Austria.

E-mail address: maik.bieleke@univie.ac.at (M. Bieleke).
} 
format; Chapman et al., 2009). In what follows, we derive two aspects that should be incorporated in a measure of if-then planning based on implementation intention theory.

\subsection{The structure of the plan: if-part and then-part}

If-then plans owe their name to the fact that they consist of two components (Gollwitzer, 1993, 1999): The if-part pertains to a critical situation in which one wants to act while the then-part pertains to a goal-directed behavior that one wants to perform in that situation. Importantly, this is not merely a conceptual distinction: Specifying situations in the if-part and linking them to behaviors in the then-part is assumed to elicit distinct cognitive processes that underlie the behavioral effects of if-then plans (Webb \& Sheeran, 2007). First, the mental representation of the critical situation specified in the if-part becomes activated and accessible, making it more likely that the situation is attended to and recognized (e.g., Webb \& Sheeran, 2004). Second, an associative link is forged between that situation and the behavior specified in the then-part that permits an automatic initiation of the planned behavior (e.g., Brandstätter et al., 2001). Therefore, a measure of if-then planning should comprise items tapping into elements of the ifpart (i.e., identifying critical situations) and the then-part (i.e., planning goal-directed behaviors) to fully capture the cognitive processes of ifthen planning.

\subsection{The focus of the plan: seizing opportunities and overcoming obstacles}

A measure of if-then planning should take into account whether planning is geared towards seizing opportunities or towards overcoming obstacles, thereby capturing two fundamental types of plans (Gollwitzer, 2014; Sheeran \& Webb, 2016). In a plan geared towards seizing opportunities, critical situations are conducive to goal progress or crucial for attaining the goal, and the goal-directed behavior focuses on utilizing them. In a plan geared towards overcoming obstacles, critical situations can be temptations that interfere with goal progress or jeopardize goal attainment, and the goal-directed behavior focuses on hedging against them. Again, this is not merely a conceptual distinction. For instance, opportunity-focused plans are especially important for initial progress towards the goal (i.e., getting started), whereas obstaclefocused plans are crucial for sustained progress (i.e., staying on track; Gollwitzer \& Oettingen, 2011; Sniehotta et al., 2005).

\subsection{The present research}

There is a blind-spot in the literature on if-then planning regarding the question of whether people differ in their tendency to make if-then plans across various goals. To address this gap, we ran a series of three studies in which we developed and validated the If-Then Planning Scale (ITPS). Item generation was grounded in implementation intention theory (Gollwitzer, 1999). We initially generated 16 items (Table 1) for an assessment of, first, the inclination to think about components of the if-part and components of the then-part and, second, the tendency to prepare for seizing opportunities and overcoming obstacles. Therefore, eight items covered aspects of the if-part (i.e., identifying critical situations), with one half of the items related to seizing opportunities and the other half to overcoming obstacles. The other eight items covered aspects of the then-part (i.e., specifying goal-directed behaviors), with again one half related to taking advantage of opportunities and the other half related to dealing with obstacles. Our idea was that these items represent a general tendency to engage in if-then planning. For instance, people who intuitively form implementation intentions should score highly on items pertaining to both the if-part and the then-part.

In Studies $1 \mathrm{a}$ and $1 \mathrm{~b}$, we drew on two independent samples to establish the psychometric qualities of the ITPS and to examine its associations with goal attainment. In Study 2, we demonstrated the convergent and discriminant validity of the scale against a battery of
Table 1

Items developed for the ITPS based on implementation intention theory.

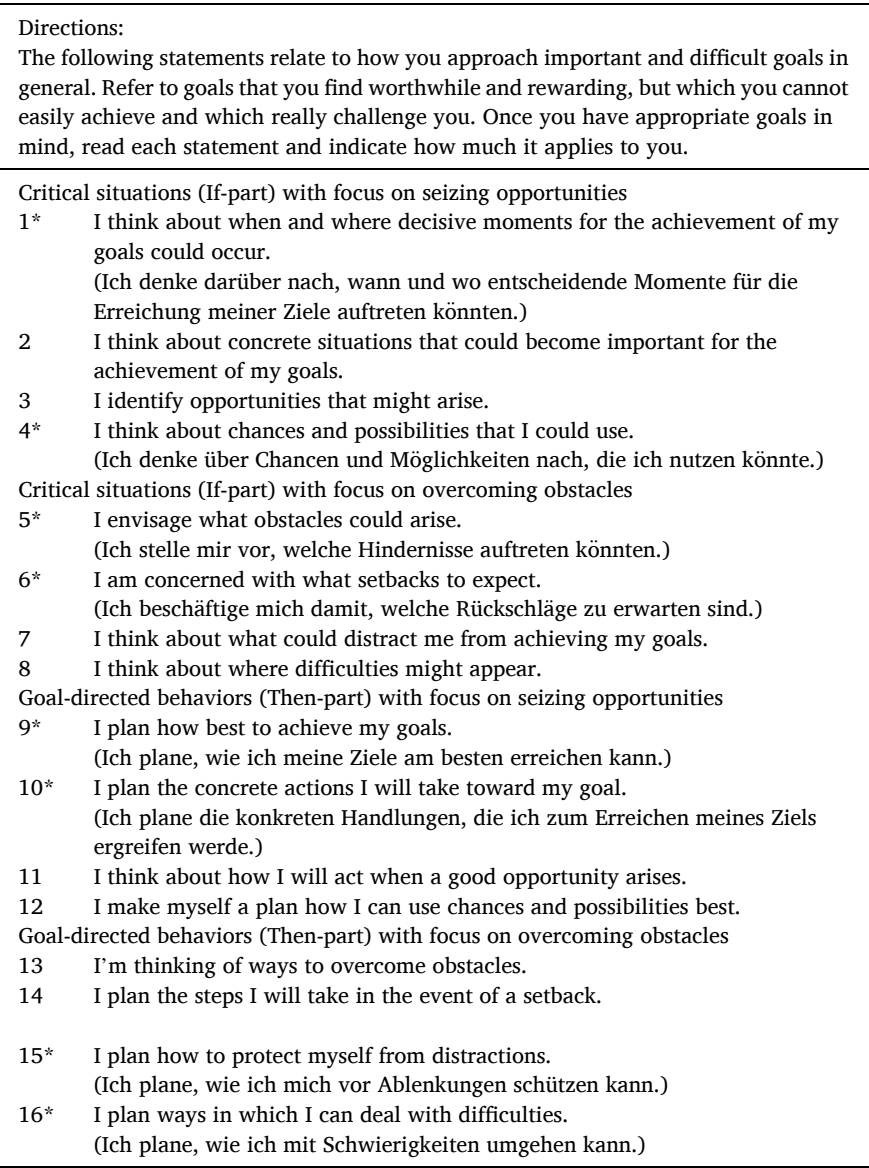

Note. Items marked with an asterisk constitute the ITPS, their translation into German is provided in brackets.

established instruments. In Study 3, we analyzed the relationship of the ITPS with academic achievement in a sample of high school students and examined mediators of if-then planning effects according to implementation intention theory. Across studies, we investigated whether ifthen planning as measured by the ITPS is meaningfully related to demographic characteristics (e.g., socioeconomic status). All data, materials, and analyses are available at OSF (osf.io/w9635).

\section{Studies 1a and 1b: establishing the ITPS, its psychometric qualities, and its associations with goal attainment and demographic characteristics}

The first aim of Study 1 was to examine the psychometric characteristics of the 16 items initially generated for the ITPS and to derive a short and efficient, yet reliable scale that covers the conceptual scope of if-then planning. We used exploratory factor analyses (EFA) in Study 1a and expected the data to be best described by a model with four correlated factors, corresponding to the four aspects of if-then plans that guided the item generation (i.e., critical situation vs. goal-directed behavior $\times$ seizing opportunities vs. overcoming obstacles). We followed this up with confirmatory factor analysis (CFA) in Studies 1a and $1 \mathrm{~b}$ to establish that these four factors are governed by a higher-order factor, representing the tendency to engage in if-then planning and justifying an aggregation of the ITPS into a single score.

The second aim of Study 1 was to investigate associations of the ITPS with successful goal attainment, unsuccessful goal attainment, and demographic characteristics (age, gender, socioeconomic status). With respect to successful goal attainment, we focused on pro-environmental 
behavior because most people have at least some pro-environmental goals that they struggle to attain (Yuriev et al., 2020) and if-then plans are known to be helpful in that regard (e.g., Grimmer \& Miles, 2017). Thus, we expected higher ITPS scores to be associated with better attainment of pro-environmental goals, especially among people who find these goals important but difficult to attain. With respect to unsuccessful goal attainment, we focused on feelings of distress that accompany a lack of progress towards a goal. If-then planning involves higher goal-related investments (e.g., thinking about critical situations and behaviors) that should make failures more costly. We thus expected an association between ITPS scores and feelings of distress related to the failure to make progress towards one's goals. We additionally accounted for self-esteem because the facilitating effects of if-then planning on goal attainment should boost self-esteem among people with higher ITPS scores (e.g., Oettingen \& Gollwitzer, 2010). Finally, we explored associations between the ITPS and demographic characteristics. In particular, we expected a positive association between the ITPS and socioeconomic status (SES) because higher SES is related to better selfregulation in general (Moffitt et al., 2011) and if-then planning in particular (Prenda \& Lachman, 2001).

\subsection{Participants and procedure}

Based on sample size recommendations for factor analysis (Mundfrom et al., 2005), we recruited 629 participants for Study 1a and 607 participants for Study 1b via Amazon's MTurk. We invited only reputed workers ( $\geq 90 \%$ approval rate, $\geq 100$ HITS), used captchas to guard against bots, and mixed in a validity check item ("I have tried to answer all these questions honestly and accurately") for 101 participants in Study 1a. Worker reputation is similarly effective but less controversial than attention checks to ensure data quality on MTurk (Peer et al., 2014). Moreover, $97 \%$ of the subsample strongly agreed with the validity check. Twenty-three participants in Study $1 \mathrm{a}$ and eight participants in Study $1 \mathrm{~b}$ did not finish the study, leaving 606 (age: $M=39.6, S D=$ 11.5 ; $43.9 \%$ female) and 599 participants (age: $M=36.6, S D=11.4$; $43.7 \%$ female), respectively. Additional demographic information is provided in Table S1.

\subsubsection{ITPS}

Participants responded to the ITPS items in a randomized order on Likert scales ( $1=$ strongly disagree, $7=$ strongly agree $)$. We used the initial set of 16 items in Study 1a and a streamlined set of eight items in Study $1 \mathrm{~b}$ (see below). The items were presented at the beginning of each study, using directions that geared participants towards thinking of desirable but difficult goals (Table 1).

\subsubsection{Environmental goals}

Afterwards, we instructed participants to think of their environmental goals (e.g., recycling waste, saving energy, buying organic food) and presented three visual analogue scales $(0=$ strongly disagree, $100=$ strongly agree) to measure the attainment of these goals ("I am successful in achieving my environmental goals") as well as their importance ("It is important and rewarding for me to achieve my environmental goals") and difficulty ("I find it difficult and challenging to achieve my environmental goals").

\subsubsection{Distress related to failure of goal progress and self-esteem}

In Study 1b, we assessed experiences of distress that participants associated with the failure to make goal progress using a set of three items ("I feel disappointed or annoyed by myself," "I feel ashamed or embarrassed," "I feel uneasy or bothered;" Cronbach's $\alpha=0.88$; Elliot \& Devine, 1994). Answers were provided on visual analogue scales ( $0=$ strongly disagree, $100=$ strongly agree) and averaged into a single score. We added one item measuring participants' generalized self-esteem ("I have high self-esteem;" Robins et al., 2001) that participants answered on a Likert scale $(1=$ not very true of me, $5=$ very true of $m e)$.

\subsubsection{Demographics and socioeconomic status (SES)}

Finally, we assessed age, gender, and SES (Table S1). As indicators of objective SES, we asked for annual income, level of education, and employment status. Regarding subjective SES, participants indicated their position on a hypothetical ladder (Adler et al., 2000) ranging from 1 (least money, education, and respected jobs) to 7 (most money, education, and respected jobs).

\subsection{Additional variables}

For a preliminary analysis, 101 participants in Study 1 a received the NEO-FFI-3 (McCrae \& Costa, 2007). As Study 2 comprised a larger-scale investigation of personality with compatible results, we refrain from reporting details.

\subsection{Results and discussion}

\subsubsection{Exploratory factor analyses (EFA) and ITPS construction (Study 1a)}

We subjected data from Study 1a to EFA models comprising up to four correlated factors using an oblimin rotation procedure. We relied on ML estimation with robust standard errors in Mplus (Version 8; Muthén \& Muthén, 1998-2017). As goodness-of-fit measures, we determined the root mean squared error of approximation (RMSEA), the standardized root mean square residual (SRMR), the comparative fit index (CFI), the Tucker-Lewis Index (TLI), and the $\chi^{2}$ value. Good model fit was assumed when RMSEA $\leq 0.06$, SRMR $\leq 0.08$, and CFI and TLI $\geq 0.95$ (Hu \& Bentler, 1999). To evaluate comparative fit, we compared the goodnessof-fit of each model to a model with one factor less (with lower RMSEA/ SRMR and higher CFI/TLI indicating better fit) and tested the significance of the $\chi^{2}$ difference value $\left(\Delta \chi^{2}\right)$.

We started with the full set of 16 items developed for the ITPS and administered them to participants in Study 1a. A model with four factors showed very good fit, RMSEA $=0.041$, SRMR $=0.019, \mathrm{CFI}=0.979$, TLI $=0.960, \chi^{2}(62)=126.11, p<.001$, and was superior to models comprising fewer factors (Table S2). The four factors corresponded well to the four conceptual aspects of if-then planning on which item generation was based (Table S3) and were substantially and positively correlated $(0.30 \leq r \leq 0.70)$.

We observed that at least two items loaded highly on each factor without displaying cross-loadings (Table S3), while not every factor had three such items. Because we were aiming for a short and efficient scale that gives equal weight to each conceptual aspect of if-then planning, we thus selected these two items as being most representative of the corresponding aspect (flagged with asterisks in Table 1) with one exception: We selected Item 15 instead of Item 14 to avoid large overlaps in item content. We then reran the EFA on the resulting set of eight items. A model with four factors remained superior and showed excellent fit (Table S2), RMSEA $=0.000$, SRMR $=0.001, \mathrm{CFI}=1.000, \mathrm{TLI}=1.000$, $\chi^{2}(2)=0.22, p=.897$. This four-factor structure again corresponded well to the four conceptual aspects of implementation intentions (Table S3) and the factor correlations remained sizeable $(0.34 \leq r \leq$ 0.68 ). This suggests that the selected eight items capture the conceptual scope of if-then planning as laid out in implementation intention theory, and we, therefore, proceeded with this set of items in all subsequent analyses after some minor adjustments of the item wording.

\subsubsection{Confirmatory factor analysis (CFA) and aggregation of the ITPS (Studies $1 a$ and $1 b$ )}

Next, we investigated whether the four factors extracted by EFA are governed by a single higher-order factor. We subjected data from the eight selected items to a CFA and examined the fit of a model with four lower-order factors as well as a fifth, higher-order factor on which each of the lower-order factors loaded. This model showed very good fit in Study 1a (Fig. S1), RMSEA $=0.058$, SRMR $=0.038$, CFI $=0.970$, TLI $=$ 0.947, $\chi^{2}(16)=48.82, p<.001$, and in Study 1b (Fig. S2), RMSEA $=$ $0.047, \mathrm{SRMR}=0.034, \mathrm{CFI}=0.981, \mathrm{TLI}=0.966, \chi^{2}(16)=36.89, p=$ 
.002. This indicates that the eight items can be holistically interpreted in terms of a tendency to engage in if-then planning. This is further corroborated by the internal consistency of the ITPS in terms of Cronbach's $\alpha$ (Study 1a: 0.85, Study 1b: 0.84), which encourages the use of the average ITPS score as a measure of individual differences in if-then planning (Study 1a: $M=5.27, S D=0.95$; Study $1 \mathrm{~b}: M=5.32, S D=$ 0.87). In fact, because each lower-order factor comprises only two highly correlated items, they are not suitable for assessing the conceptual aspects of if-then planning and we thus recommend relying on the overall ITPS score.

\subsubsection{The ITPS and successful goal attainment (Studies $1 a$ and $1 b$ )}

We regressed the success of attaining environmental goals on the ITPS (Tables S4 and S5), which emerged as a significant predictor in Study $1 \mathrm{a}, b=7.09, S E=1.00,95 \%$ CI $[5.12,9.05], \beta=0.28, p<.001$, and in Study $1 \mathrm{~b}, b=6.30, S E=1.05,95 \%$ CI $[4.24,8.36], \beta=0.24, p<$ .001 . As this could merely reflect that participants with higher ITPS scores are more strongly committed to these goals or perceive them as easier, we adjusted for the importance and difficulty of the goal and their interaction effect (i.e., the expected value). Attesting to its explanatory power, the ITPS was still a significant predictor in a model together with these three variables in Study $1 \mathrm{a}, b=2.02, \mathrm{SE}=0.81,95 \%$ CI $[0.43$, 3.62], $\beta=0.08, p=.013$, and Study $1 \mathrm{~b}, b=2.34$, SE $=0.89,95 \% \mathrm{CI}$ [0.59, 4.09], $\beta=0.09, p=.009$. Hence, participants with higher ITPS scores were more likely to report successful attainment of proenvironmental goals, even after accounting for their importance, difficulty, and expected value. Finally, we also specified interactions between the ITPS and importance, difficulty, and their interaction. Except for the interaction between the ITPS and difficulty in Study 1b, these interactions were all significant, $p \leq .024$. Inspecting the data revealed that the more important and/or the more difficult the goal was, the more strongly were higher ITPS scores associated with better goal attainment.

\subsubsection{The ITPS and unsuccessful goal attainment (Study 1b)}

We regressed experiences of distress associated with failures of making goal progress on the ITPS, which did not emerge as a significant predictor, $b=1.20, S E=1.29$, 95\% CI $[-1.34,3.74], \beta=0.04, p=.353$. However, as expected, higher ITPS scores were correlated with higher self-esteem, $r(597)=0.17,95 \%$ CI $[0.09,0.25], p<.001$, which might have masked the proposed association between ITPS and distress. Indeed, after adjusting for self-esteem the ITPS score was a significant predictor of experiences of distress, $b=3.44, S E=1.20,95 \%$ CI [1.09, 5.79], $\beta=0.11, p=.004$. That is, given a certain level of self-esteem, participants with higher ITPS scores reported stronger feelings of distress when failing to make progress towards their goals.

\subsubsection{Correlations between the ITPS and demographic characteristics (Studies $1 a$ and $1 b$ )}

The ITPS did not correlate with age in Study 1a, $r=0.05$, 95\% CI $[-0.04,0.13], p=.281$, and Study $1 \mathrm{~b}, r=0.02,95 \%$ CI $[-0.06,0.10], p$ $=.656$. The correlation with gender was insignificant in Study 1a, $r=$ $-0.05,95 \%$ CI $[-0.13,0.03], p=.191$, whereas male participants displayed lower ITPS scores than female participants in Study $1 \mathrm{~b}, r=0.10$, $95 \%$ CI [0.02, 0.18], $p=.011$. In both studies, higher ITPS scores were associated with higher income, $r=0.17,95 \%$ CI [0.09, 0.24], $p<.001$, and $r=0.10,95 \%$ CI $[0.02,0.18], p=.016$, and higher subjective SES, $r$ $=0.22,95 \%$ CI $[0.15,0.30], p<.001$, and $r=0.10,95 \%$ CI $[0.02,0.18]$, $p=.016$, but not with education, $r \approx 0.00,95 \%$ CI [ $-0.08,0.08], p=$ .927 , and $r=0.05,95 \%$ CI [ $-0.03,0.13], p=.182$. Taken together, the expected association between the ITPS and indicators of SES emerged apart from education. No associations emerged with age and our findings regarding gender were mixed.

\section{Study 2: convergent and discriminant validity of the ITPS}

Having established the structure of the ITPS, we examined its convergent and discriminant validity in Study 2 . We used a battery of questionnaires to assess (1) general self-regulatory styles, (2a) manifestations of vigorous self-regulation and (2b) of poor self-regulation, (3) motivational styles, (4) cognitive styles, and (5) facets of personality that should be related to if-then planning based on existing research (Bieleke, Keller, \& Gollwitzer, n.d.). We organize our hypotheses around these five categories rather than around individual (sub)scales to avoid redundancies for scales that tap into the same category.

As forming implementation intentions constitutes an effective selfregulation strategy (Gollwitzer, 2014; Keller et al., 2020) and because most self-regulation inventories cover some aspects of planning (e.g., Carey et al., 2004), we expected strong positive correlations between the ITPS and measures of self-regulatory styles. We included a broad range of these measures: the Rosenbaum Self-Control Schedule (Rosenbaum, 1980), the Brief Self-Control Scale (Tangney et al., 2004), the Capacity for Self-Control Scale (Hoyle \& Davisson, 2016), the Short Self-Regulation Questionnaire (Carey et al., 2004), the Habitual Self-Control Questionnaire (Schroder et al., 2013), the Short Grit Scale (Duckworth \& Quinn, 2009), and the Emotion Regulation Questionnaire (Gross \& John, 2003).

The frequent use of if-then planning introduces routines into goal striving (Bieleke et al., 2017; Gollwitzer et al., 2008) and we accordingly expected modest positive associations between the ITPS and vigorous manifestations of self-regulation. We examined this hypothesis with the Almost Perfect Scale Revised (Slaney et al., 2001), the Obsessive-Compulsory Inventory (Foa et al., 2002), and the Preference for Routines subscale of the Creature of Habit Scale (Ersche et al., 2017). By analogy, routines can shield against lapses in goal striving and we, therefore, expected modest negative associations between the ITPS and manifestations of poor self-regulation. These were measured with the Procrastination Scale (Tuckman, 1991), the Barrett Impulsiveness Scale (Patton et al., 1995), and the Eating-Related Automaticity Subscale of the Creature of Habit Scale (Ersche et al., 2017).

If-then planning is conceptually rooted in an action-oriented mindset (Keller et al., 2019) and is therefore characterized by an inherent focus on initiating action (i.e., performing goal-directed behaviors). We accordingly expected positive correlations between the ITPS and activating (vs. inhibiting) as well as action-oriented (vs. state-oriented) motivational styles. We thus included the Behavioral Inhibition and Activation Scale (Carver \& White, 1994) and the Action Control Scale (Kuhl, 1994). Furthermore, if-then planning requires deliberation, forethought, and prospective memory to commit to a course of action (Gollwitzer \& Brandstätter, 1997; Martiny-Huenger et al., 2016), which is why we assumed modest positive relations between the ITPS and deliberation-focused (vs. intuitive) cognitive styles as well as preferences for resolving ambiguity. We tested this by including scales measuring Consideration of Future Consequences (Strathman et al., 1994), Need for Cognition (Cacioppo et al., 1984), and Need for Cognitive Closure (Kruglanski et al., 1993). Finally, we included the Big Five Inventory-2 Short (Soto \& John, 2017), the Rosenberg Self-Esteem Scale (Rosenberg, 1965), and the Dirty Dozen Scale (Jonason \& Webster, 2010) to check whether the ITPS is associated with personality facets that are conceptually close to if-then planning (e.g., conscientiousness) and to establish discriminant validity concerning unrelated constructs (e.g., dirty dozen).

\subsection{Participants and procedure}

A power analysis suggested a minimum sample size of about 250 participants for detecting small-to-medium correlations (two-tailed, $\alpha=$ 0.05 , power $=0.90$; see also Schönbrodt \& Perugini, 2013). We recruited 932 participants on Amazon's MTurk who worked on the ITPS (Cronbach $\alpha=0.85, M=5.20, S D=0.95$ ) and a subset of the 20 other questionnaires (Table S6). Each participant received four short (8 to 20 items) and two long questionnaires ( 23 to 42 items) that were randomly selected, providing us with data from about 300 participants for estimating each correlation while ensuring reasonable workloads. The 
position of the ITPS among the questionnaires was randomized and demographic questions were always presented last. Thirty-seven participants did not complete the study, resulting in a final sample of 895 participants (43.5\% female) with a mean age of $M=37.1$ years $(S D=$ 11.1).

\subsection{Results and discussion}

\subsubsection{Correlations between the ITPS, demographic variables, and SES}

Again, the ITPS did not correlate significantly with age, $r(886)=$ $0.03,95 \%$ CI $[-0.03,0.10], p=.323$, or gender, $r(881)=0.01,95 \%$ CI $[-0.05,0.08], p=.681$. Higher ITPS scores were associated with higher income, $r(886)=0.14,95 \%$ CI $[0.07,0.20], p<.001$, and higher subjective SES, $r(886)=0.14,95 \% \mathrm{CI}[0.08,0.21], p<.001$. This replicated findings from Studies $1 \mathrm{a}$ and $1 \mathrm{~b}$; however, this time a correlation with education emerged as well, $r(886)=0.11,95 \%$ CI $[0.04,0.17], p=.001$.

\subsubsection{Correlations between the ITPS and other questionnaires}

Correlations between the ITPS and other questionnaires are detailed in Table S6 and we focus here on key observations.

(1) Self-regulatory styles. As expected, we found sizeable positive correlations between the ITPS and scales assessing self-regulatory styles $(0.23 \leq r \leq 0.61)$. Interestingly, the ITPS correlated only weakly with individual subscales that are not associated with effective self-regulation per se (e.g., suppression as an emotion regulation strategy, $r=0.12$ ), speaking to the discriminant validity of the ITPS. The overlap between the ITPS and the various self-regulation questionnaires peaked at $37 \%$ of shared variance, suggesting that the ITPS measures a genuine construct.

(2a) Manifestations of vigorous self-regulation. The ITPS showed the predicted positive and moderate correlations with indicators of vigorous self-regulation $(0.16 \leq r \leq 0.36)$. The ITPS scores were associated with an adaptive form of perfectionism (i.e., higher standards, $r=$ 0.59 , but not higher discrepancy, $r=0.08$ ) and weak but consistently positive correlations emerged with facets of obsessive-compulsive behavior, $r \leq 0.21$. Finally, higher ITPS scores were associated with a preference for routines, $r=0.19$.

(2b) Manifestations of poor self-regulation. We found the predicted moderate negative correlations between the ITPS and manifestations of poor self-regulation. Specifically, participants with higher ITPS scores procrastinated less, $r=-0.35$, and reported less impulsivity, $r=-0.22$, especially regarding those facets of impulsivity that pertains to a lack of forethought and planning, $r=-0.46$. No significant association was found with the degree of eating-related automaticity, $r=$ 0.07 .

(3) Motivational styles. In line with our predictions, the ITPS was positively correlated with activation-oriented, $r \geq 0.18$, and actionoriented styles, $r \geq 0.13$, whereas no correlation emerged with behavioral inhibition, $r=0.03$. The observed correlations were consistent but mostly small, except for two strong correlations between the ITPS and the drive to follow goals, $r=0.52$, and with the responsiveness to rewards, $r=0.45$.

(4) Cognitive styles. As predicted, moderate positive correlations emerged between ITPS scores and deliberation-focused cognitive styles as well as need for cognitive closure as a measure of the preference to resolve ambiguity $(0.20 \leq r \leq 0.30)$.

(5) Facets of personality. We found positive correlations of the ITPS with the Big Five personality traits of open-mindedness, conscientiousness, extraversion, and agreeableness, $r \geq 0.22$, as well as a negative correlation with negative emotionality, $r=-0.16$. As expected, the most sizeable correlation pertained to conscientiousness, $r=0.36$, which is conceptually most closely related to planning (e.g., Ludwig et al., 2019). Replicating Study 1b, a positive correlation emerged between ITPS and self-esteem, $r=0.34$. Finally, no correlation emerged between the ITPS and Machiavellianism, $r=0.06$, and psychopathy, $r=-0.04$, attesting to the discriminant validity of the ITPS. However, a small but significant positive correlation with narcissism emerged, $r=0.14$.

\section{Study 3: automaticity, goal-directed behaviors, and academic achievement}

Our aim for conducting Study 3 was threefold. First, we recruited a sample of high school students who worked on the questionnaires in person rather than online. Second, we focused on academic achievement as an additional outcome variable for which if-then planning is beneficial (e.g., Webb et al., 2007). Third, we assessed two established mediators of implementation intention effects: the automaticity of goal striving and the performance of goal-directed behaviors (Webb \& Sheeran, 2007). We assumed that individual differences in if-then planning are associated with better academic achievement in terms of school grades. Further, based on implementation intention theory we hypothesized that this relationship is mediated by the performance of goal-directed behaviors, and that the relationship between if-then planning and goal-directed behaviors is mediated by automatic goal striving (i.e., sequential mediation). That is, we expected that the association of the ITPS with more automatic goal striving is conveyed via strategic automaticity, which in turn should benefit academic achievement by facilitating the performance of goal-directed behaviors.

\subsection{Participants and procedure}

We recruited 576 students (79.2\% female) from various high schools in southern Germany who attended an informational open house about studying at the university. The event lasted for three days and we collected data from as many students as possible during this time. The mean age of this sample was accordingly lower than in our previous studies $(M=17.2$ years, $S D=2.9$ ), which is why we did not include the objective and subjective SES assessments. We used a back-translation procedure to translate the ITPS items into German. Unfortunately, two items of the ITPS were mixed up during the translation with already discarded items from the initial item pool and were mistakenly administered to participants. However, as these items pertained to the same conceptual aspect of if-then planning as the intended items (i.e., critical situations with focus on overcoming obstacles), we could still use the data. The internal consistency of the ITPS in terms of Cronbach $\alpha$ was 0.72 and thus a little lower than in our previous studies, which might have been caused by inadvertently changing items, the more inexperienced participants, or might be the result of translating the items to German. The average ITPS score was also slightly lower, $M=4.97$ ( $S D=$ 0.74).

\subsubsection{Validity check}

We included a validity check item to assess the motivation to work carefully ("How important was it to you to carefully complete the questionnaire?"; 1 = not important at all, 7 = very important). Most participants $(96.7 \%)$ selected values of 3 or more $(M=5.2, S D=1.3)$, indicating motivation to provide meaningful answers.

\subsubsection{Academic achievement}

We measured academic achievement by asking for recent grades in three core school subjects (i.e., German, English, and mathematics). In the German high school system, grades are expressed on a scale from 0 (worst) to 15 (best) points. We averaged grades across subjects into a single score reflecting academic achievement.

\subsubsection{Automatic goal striving}

To assess the automaticity of goal striving, we adapted four items from the Self-Report Habit Index (Verplanken \& Orbell, 2003). Analogous to the ITPS, we framed these items in terms of general goal striving instead of a specific goal or behavior: "After I set myself a goal, I automatically work towards it," "I do not have to consciously remember working towards my goals," "I work towards my goals without thinking," and "I often only realize afterwards that I have just worked towards my goals" (Cronbach's $\alpha=0.59$ ). Participants answered on 
Likert scales ( 1 = does not apply at all, 7 = does fully apply) and an average score was computed.

\subsubsection{Performance of goal-directed behavior}

Finally, participants answered two questions tapping into the performance of goal-directed behaviors in the domain of academic achievement. One question pertained to preparing for exams ("How often do you manage to prepare sufficiently for exams?") and the other one pertained to preparing for lessons ("How often do you experience negative consequences at school because of things you have forgotten [e. g. homework, books, sports stuff]?"; reverse-coded), $r(562)=0.27,95 \%$ CI $[0.19,0.34], p<.001$. Participants responded on Likert scales $(1=$ never, $7=$ very often) and we averaged their answers into a single score.

\subsection{Results and discussion}

\subsubsection{Correlations between the ITPS and other constructs}

As in the previous studies, the ITPS did not correlate with age, $r(567)$ $=0.05,95 \%$ CI $[-0.03,0.13], p=.255$. Unlike Studies $1 \mathrm{a}$ and 2 but analogous to Study $1 \mathrm{~b}$, it was correlated with gender, $r(552)=0.10$, $95 \%$ CI $[0.02,0.18], p=.015$, such that male participants displayed lower ITPS scores than female participants. Importantly, we observed positive and significant correlations between the ITPS score and the main variables in our study: automatic goal striving, $r(567)=0.25,95 \%$ CI [0.18, 0.33], $p<.001$, performance of goal-directed behavior, $r(566)$ $=0.21,95 \%$ CI [0.14, 0.29], $p<.001$, and academic achievement, $r$ $(546)=0.14,95 \%$ CI $[0.06,0.22], p<.001$.

\subsubsection{Sequential mediation model}

To test our hypotheses regarding the relationship between individual differences in if-then planning and academic achievement, we conducted a sequential mediation analysis in Mplus. We evaluated the significance based on bias-corrected bootstrap confidence intervals with 10,000 samples (i.e., effects are significant if the confidence interval excludes 0 ). We specified a direct effect of the ITPS score on academic achievement as well as three indirect effects: via automated goal striving, via the performance of goal-directed behavior, and via automated goal striving and the performance of goal-directed behavior (Fig. 1). As expected, a significant total effect suggested that a higher ITPS score was associated with better academic achievement, $b=0.42,95 \%$ CI $[0.17$, $0.67], \beta=0.14$. This finding was driven by the significant joint indirect effect, $b=0.25,95 \%$ CI $[0.13,0.38], \beta=0.09$, whereas the direct effect was not significant, $b=0.17,95 \%$ CI $[-0.09,0.42], \beta=0.06$.

Turning to the indirect effects, we found that a higher ITPS score was associated with performing more goal-directed behaviors, $b=0.25$, 95\% CI $[0.12,0.38], \beta=0.16$, which was in turn associated with better academic achievement, $b=0.68,95 \% \mathrm{CI}[0.51,0.86], \beta=0.37$, giving rise to a significant indirect effect via performance of goal-directed behavior, $b=0.17,95 \%$ CI [0.07, 0.27], $\beta=0.06$. Moreover, a higher ITPS score was associated with more automatic goal striving, $b=0.31$, 95\% CI $[0.20,0.43], \beta=0.06$, which was associated with more performance of goal-directed behavior, $b=0.30,95 \%$ CI $[0.18,0.41], \beta=0.23$, resulting in a significant indirect effect via automatic goal striving and performance of goal-directed behavior, $b=0.06,95 \%$ CI [0.03, 0.10], $\beta$ $=0.02$. Finally, automatic goal striving itself was not significantly associated with academic achievement, $b=0.05,95 \%$ CI [ $-0.15,0.25]$, $\beta=0.02$, rendering the indirect effect via automated goal striving insignificant, $b=0.02,95 \%$ CI $[-0.05,0.08], \beta=0.01$. As such, the model is consistent with central predictions about the automaticity of implementation intentions (Webb \& Sheeran, 2007), although it should be noted the cross-sectional nature of our data and the potential for common-method bias make it difficult to draw conclusions about the temporal sequence or causality of the observed relationships. With that in mind, the predicted association between if-then planning and academic achievement was at least partially mediated by automated goal striving, which in turn was associated with stronger performance of goal-directed behaviors. Additionally, the sequential mediation model suggests that there is another pathway via the performance of goaldirected behaviors that is not mediated by automaticity. So, both findings are consistent with the view that a high propensity for if-then planning facilitates the performance of goal-directed behavior in the academic domain which in turn leads to better achievement. This suggests that if-then planning might work by facilitating both automatic and more controlled behaviors. However, neither if-then planning nor automatic goal striving seems to directly affect academic achievement which makes sense from the perspective of implementation intentions: Planning in an if-then format facilitates the detection of suitable opportunities to act and therefore increases the chance of performing goaldirected behaviors. Planning, therefore, is an important but not a sufficient prerequisite of successful goal attainment, which requires goaldirected behaviors to be performed.

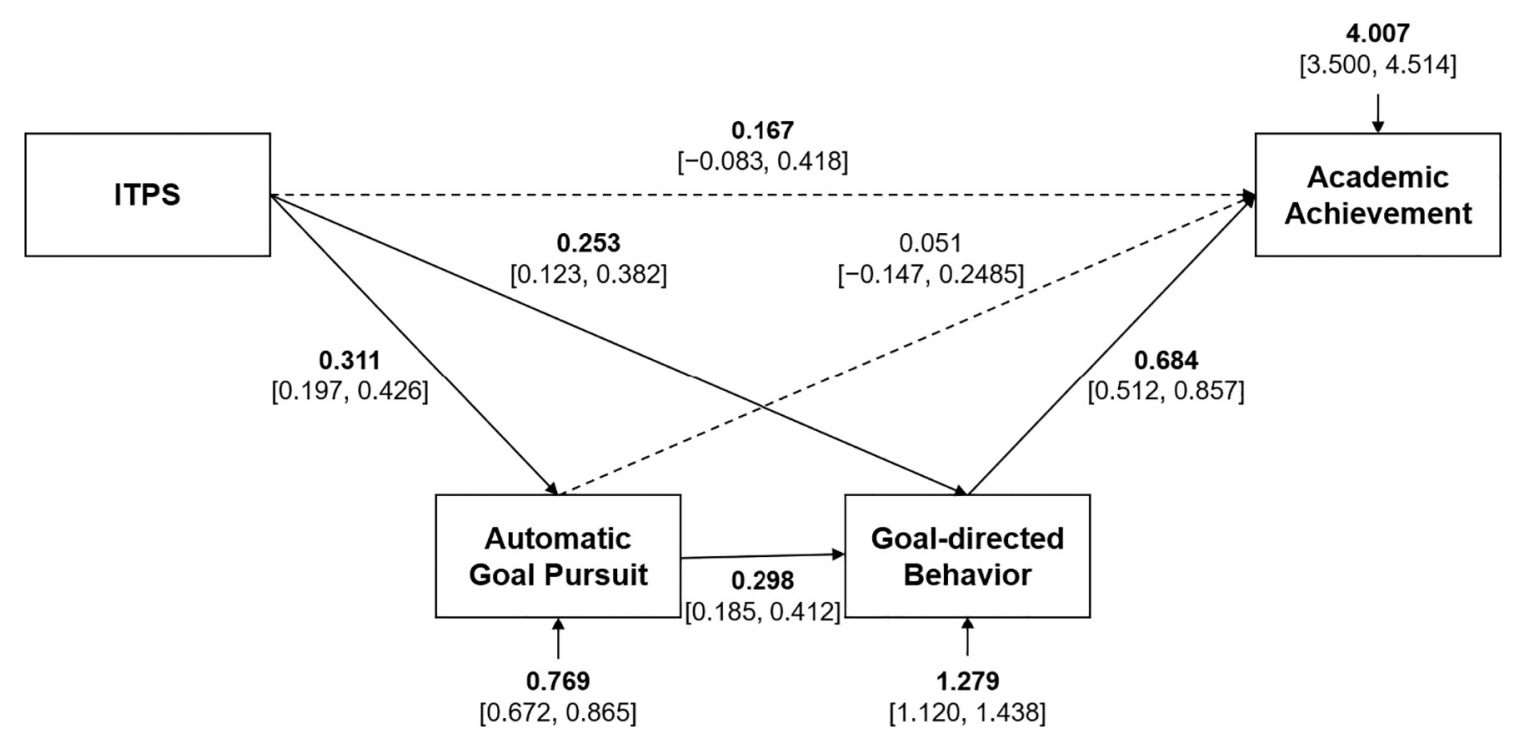

Fig. 1. Sequential mediation model in Study 3.

Unstandardized coefficients with 95\% CI. Bold coefficients and solid lines are significant, insignificant paths are dashed. 


\section{General discussion}

Across three studies, we demonstrated meaningful individual differences in the tendency to make if-then plans. We capitalized on implementation intention theory to develop the If-Then Planning Scale (ITPS) as an efficient and reliable measure of these differences. Besides showing desirable psychometric qualities, the ITPS was associated with successful goal attainment (Studies 1a \& 1b), socioeconomic status (Studies 1a, 1b, \& 2), and academic achievement (Study 3). Moreover, it displayed convergent and discriminant validity against a battery of established measures (Study 2) and exhibited meaningful relationships with goal-related distress and self-esteem (Study 1b). Finally, the ITPS was associated with automatic goal striving and the performance of goal-directed behaviors, both of which mediated its relationship with achievement (Study 3). These results provide a valuable complement to experimental research on implementation intention theory (Gollwitzer, 1999, 2014), showing that individuals differ meaningfully in their ifthen planning with consequences for goal striving and attainment.

\subsection{Associations with SES and goal attainment}

People who tended to engage in if-then planning scored higher on objective and subjective SES, the exception being education. Assuming that self-regulation can play a causal role for SES (Moffitt et al., 2011), there are at least two plausible explanations for the latter finding: The level of education is difficult to control by the individual (e.g., dependence on the family) and it might hinge on individual aspirations (e.g., when a high school diploma is sufficient for the desired job). Nevertheless, an association between if-then planning and academic achievement at a given level of education remains plausible, and this is what we observed in Study 3. Note that we are not suggesting a monocausal link between the ITPS and SES; rather, we expect that both constructs influence each other. Regarding demographics, women scored slightly higher on the ITPS than men in two studies, which fits to inconsistent trends for women to score higher on some aspects of conscientiousness than men (Costa et al., 2001). Considered jointly with the lack of an association between the ITPS and age, our results suggest that if-then planning is not specific for these demographic groups.

We additionally observed positive associations between if-then planning and the attainment of pro-environmental goals in Studies 1a and $1 \mathrm{~b}$, a domain with few but consistent findings regarding the beneficial effects of if-then planning (e.g., Grimmer \& Miles, 2017). In other applied settings, however, research on if-then planning is even scarcer and results are less conclusive (e.g., endurance sport; Wolff et al., 2019). Focusing on individual differences in if-then planning can help addressing this research gap in at least two ways. First, it allows gauging the potential impact of if-then planning before conducting intricate intervention studies. Second, it allows researchers to identify individuals who are more versus less likely to make if-then plans unprompted (e.g., Wolff et al., 2020). An avenue for further research is investigating settings beyond the pro-environmental and academic domains.

\subsection{Characteristics of goal striving}

Experimental research on implementation intention has demonstrated that if-then plans promote goal attainment because they automate and thereby facilitate the performance of goal-directed behaviors (Webb \& Sheeran, 2007). Our findings support this reasoning from an individual difference perspective. If-then planners perceived their goal striving as more automatic in Study 3, which was associated with higher academic achievement via the performance of goal-directed behaviors. However, if-then planning was not exclusively associated with better achievement through automaticity, suggesting that planning also facilitates deliberate action (see Zimmerman, 2002).

Our findings also align with research indicating that using if-then plans as a self-regulation strategy might have some undesired effects (e.g., Bieleke et al., 2017). First, people who engaged in more if-then planning reported stronger feelings of distress in connection to failures of making goal progress in Study 1b, but only when their higher selfesteem was considered. Our initial hypothesis was that thinking of proper if-then plans is an effortful endeavor in itself, making failure feel worse due to the higher initial investments compared to merely setting a goal. It is, however, also conceivable that if-then planning eases goal striving because performing goal-directed behaviors becomes automated and thus less effortful (Freydefont et al., 2016; see also Study 3), thereby leaving less room for self-defensive explanations after failure. Both mechanisms could be at work simultaneously, explaining why people who make if-then plans find compromised goal progress more distressful.

Second, people prone to engage in if-then planning appeared to be more vigorous in their goal striving. They exhibited (adaptive patterns of) perfectionism, leaned towards obsessive-compulsive behaviors, and showed preferences for routines. While these associations were modest in size, they align with research showing that if-then planning renders goal striving tenacious (e.g., Legrand et al., 2017). Our research suggest that this tenacity is genuine to individual differences in if-then planning and not merely an epiphenomenon of prompting people to make if-then plans in experimental contexts.

\subsection{Stimulating future research with the ITPS}

Prompting people to make if-then plans has sustained facilitative effects on the specified behavior (e.g., Holland et al., 2006) and can even generalize to situations similar to the specified one (e.g., Bieleke et al., 2017). However, it is unknown whether as a result of if-then planning interventions people also become more likely to make if-then plans on their own-that is, whether they transfer the process of identifying critical situations and goal-directed behaviors to new and different goals. That seems conceivable in particular when they are guided towards generating their own if-then plans (e.g., as part of a mental contrasting with implementation intentions intervention; Gollwitzer \& Oettingen, 2011) rather than receiving already formulated plans. Such training effects could be examined by administering the ITPS twice, once before conducting the intervention and once again afterwards, and then examining whether the ITPS score has increased.

The ITPS could alternatively be adapted to specific contexts by altering the directions. For instance, rather than instructing participants to think of their goals in general, they could be guided towards thinking about their goals in a specific domain (e.g., environmental, academic). In that sense, the ITPS might allow a glimpse into intra-individual differences in if-then planning (e.g., tendencies to plan in one domain but not in the other) or into specific rather than generalized effects of an ifthen planning intervention. Such an approach would be closer to existing measures of planning (e.g., Lynch et al., 2010), while still enabling researchers to cover all important conceptual aspects of if-then plans.

The ITPS could also be administered to critical samples who are known to experience difficulties with their self-regulation (e.g., people with reduced frontal lobe function). Implementation intentions are known to be helpful in such samples (Wieber et al., 2015), suggesting that these people might not be inclined to make if-then plans on their own. This might be reflected in a lower ITPS score compared to our present studies, which drew upon samples that were reasonably educated and not characterized by impaired self-regulation. This would not only be an additional validation of the ITPS but also indicate that the scale might be used as a diagnostic instrument.

Our study has limitations that future research should address. First, there is a strong association between general self-control and intelligence (Moffitt et al., 2011), which likely extends to the self-regulation strategy of if-then planning. Hence, the relationship between the ITPS and intelligence should be explicitly assessed, with a focus on the extent to which the ITPS adds incremental value for predicting goal 
achievement beyond intelligence. Second, it would be worthwhile to link the ITPS more specifically to motivational styles, for instance by using measures to assess motives explicitly (Runge \& Lang, 2019). Third, we relied on cross-sectional, self-report data in all of our studies. Therefore, future research should assess the relationship between the ITPS and objective outcome criteria (e.g., register-based grades for academic achievement) and its predictive value in longitudinal assessments. This might also help to gauge the temporal sequence and causality of relationships with other constructs (e.g., the mediators of ifthen planning effects assessed in Study 3).

\section{Conclusion}

We established if-then planning as an individual difference variable that can be efficiently and reliably measured with the newly developed and validated If-Then Planning Scale (ITPS). The ITPS is conceptually grounded in implementation intention theory and covers four different aspects of if-then planning (specifying critical situations vs. goaldirected behaviors, focus on seizing opportunities vs. overcoming obstacles). Across three studies with more than 2600 participants, we demonstrated meaningful relationships between the ITPS and (1) accomplishments across two domains (i.e., pro-environmental behavior and academic achievement), (2) a set of personality characteristics (i.e., self-regulatory styles, manifestations of vigorous and poor selfregulation, motivational and cognitive styles), and (3) characteristics of goal striving that are predicted by implementation intention theory (i. e., automaticity and goal-directed behaviors). Administering the scale can help to identify individuals that benefit the most from learning about if-then planning as a self-regulation strategy and can thereby promote further research into this important aspect of motivational psychology.

\section{CRediT authorship contribution statement}

Maik Bieleke: Conceptualization, Methodology, Software, Investigation, Formal analysis, Data curation, Visualization, Validation, Writing - original draft, Writing - review \& editing. Lucas Keller: Conceptualization, Methodology, Software, Investigation, Validation, Writing - review \& editing.

\section{Appendix A. Supplementary data}

Supplementary data to this article can be found online at https://doi. org/10.1016/j.paid.2020.110500.

\section{References}

Adler, N. E., Epel, E. S., Castellazzo, G., \& Ickovics, J. R. (2000). Relationship of subjective and objective social status with psychological and physiological functioning: Preliminary data in healthy, White women. Health Psychology, 19(6), 586-592. https://doi.org/10.1037//0278-6133.19.6.586.

Adriaanse, M. A., Vinkers, C. D. W., de Ridder, D. T. D., Hox, J. J., \& de Wit, J. B. F. (2011). Do implementation intentions help to eat a healthy diet? A systematic review and meta-analysis of the empirical evidence. Appetite, 56(1), 183-193. https://doi. org/10.1016/j.appet.2010.10.012.

Bélanger-Gravel, A., Godin, G., \& Amireault, S. (2013). A meta-analytic review of the effect of implementation intentions on physical activity. Health Psychology Review, 7 (1), 23-54. https://doi.org/10.1080/17437199.2011.560095.

Bieleke, M., Keller, L., \& Gollwitzer, P. M. (2020). If-then planning. European Review of Social Psychology. https://doi.org/10.1080/10463283.2020.1808936 (in press)

Bieleke, M., Legrand, E., Mignon, A., \& Gollwitzer, P. M. (2017). More than planned: Implementation intention effects in non-planned situations. Acta Psychologica, 184, 64-74. https://doi.org/10.1016/j.actpsy.2017.06.003.

Brandstätter, V., Lengfelder, A., \& Gollwitzer, P. M. (2001). Implementation intentions and efficient action initiation. Journal of Personality and Social Psychology, 81(5), 946-960. https://doi.org/10.1037//0022-3514.81.5.946.

Cacioppo, J. T., Petty, R. E., \& Kao, C. F. (1984). The efficient assessment of need for cognition. Journal of Personality Assessment, 48(3), 306-307. https://doi.org/ 10.1207/s15327752jpa4803 13.

Carey, K. B., Neal, D. J., \& Collins, S. E. (2004). A psychometric analysis of the selfregulation questionnaire. Addictive Behaviors, 29(2), 253-260. https://doi.org/ 10.1016/j.addbeh.2003.08.001.
Carver, C. S., \& White, T. L. (1994). Behavioral inhibition, behavioral activation, and affective responses to impending reward and punishment: The BIS/BAS scales. Journal of Personality and Social Psychology, 67(2), 319-333. https://doi.org/ 10.1037/0022-3514.67.2.319.

Chapman, J., Armitage, C. J., \& Norman, P. (2009). Comparing implementation intention interventions in relation to young adults' intake of fruit and vegetables. Psychology \& Health, 24(3), 317-332. https://doi.org/10.1080/08870440701864538.

Costa, P. T., Terracciano, A., \& McCrae, R. R. (2001). Gender differences in personality traits across cultures: Robust and surprising findings. Journal of Personality and Social Psychology, 81(2), 322-331. https://doi.org/10.1037/0022-3514.81.2.322.

Duckworth, A. L., \& Quinn, P. D. (2009). Development and validation of the Short Grit Scale (Grit-S). Journal of Personality Assessment, 91(2), 166-174. https://doi.org/ 10.1080/00223890802634290.

Elliot, A. J., \& Devine, P. G. (1994). On the motivational nature of cognitive dissonance: Dissonance as psychological discomfort. Journal of Personality and Social Psychology, 67(3), 382-394. https://doi.org/10.1037/0022-3514.67.3.382.

Ersche, K. D., Lim, T.-V., Ward, L. H. E., Robbins, T. W., \& Stochl, J. (2017). Creature of habit: A self-report measure of habitual routines and automatic tendencies in everyday life. Personality and Individual Differences, 116, 73-85. https://doi.org/ 10.1016/j.paid.2017.04.024.

Foa, E. B., Huppert, J. D., Leiberg, S., Langner, R., Kichic, R., Hajcak, G., \& Salkovskis, P. M. (2002). The obsessive-compulsive inventory: Development and validation of a short version. Psychological Assessment, 14(4), 485-496. https://doi. org/10.1037/1040-3590.14.4.485.

Freydefont, L., Gollwitzer, P. M., \& Oettingen, G. (2016). Goal striving strategies and effort mobilization: When implementation intentions reduce effort-related cardiac activity during task performance. International Journal of Psychophysiology, 107, 44-53. https://doi.org/10.1016/j.ijpsycho.2016.06.013.

Gollwitzer, P. M. (1993). Goal achievement: The role of intentions. European Review of Social Psychology, 4(1), 141-185. https://doi.org/10.1080/14792779343000059.

Gollwitzer, P. M. (1999). Implementation intentions: Strong effects of simple plans. American Psychologist, 54(7), 493-503. https://doi.org/10.1037/0003066X.54.7.493.

Gollwitzer, P. M. (2014). Weakness of the will: Is a quick fix possible? Motivation and Emotion, 38, 305-322. https://doi.org/10.1007/s11031-014-9416-3.

Gollwitzer, P. M., \& Brandstätter, V. (1997). Implementation intentions and effective goal pursuit. Journal of Personality and Social Psychology, 73(1), 186-199. https:// doi.org/10.1037//0022-3514.73.1.186.

Gollwitzer, P. M., \& Oettingen, G. (2011). Planning promotes goal striving. In K. D. Vohs, \& R. F. Baumeister (Eds.), Handbook of self-regulation: Research, theory, and applications (2nd ed., pp. 162-185). Guilford Press.

Gollwitzer, P. M., Parks-Stamm, E. J., Jaudas, A., \& Sheeran, P. (2008). Flexible tenacity in goal pursuit. In J. Y. Shah, \& W. L. Gardner (Eds.), Handbook of motivation science (pp. 325-341). Guilford Press.

Gollwitzer, P. M., \& Sheeran, P. (2006). Implementation intentions and goal achievement: A meta-analysis of effects and processes. Advances in Experimental Social Psychology, 38, 69-119. https://doi.org/10.1016/S0065-2601(06)38002-1.

Grimmer, M., \& Miles, M. P. (2017). With the best of intentions: A large sample test of the intention-behaviour gap in pro-environmental consumer behaviour. International Journal of Consumer Studies, 41(1), 2-10. https://doi.org/10.1111/ijcs.12290.

Gross, J. J., \& John, O. P. (2003). Individual differences in two emotion regulation processes: Implications for affect, relationships, and well-being. Journal of Personality and Social Psychology, 85(2), 348-362. https://doi.org/10.1037/00223514.85.2.348.

Holland, R. W., Aarts, H., \& Langendam, D. (2006). Breaking and creating habits on the working floor: A field-experiment on the power of implementation intentions. Journal of Experimental Social Psychology, 42(6), 776-783. https://doi.org/10.1016/ j.jesp.2005.11.006.

Hoyle, R. H., \& Davisson, E. K. (2016). Varieties of self-control and their personality correlates. In K. D. Vohs, \& R. F. Baumeister (Eds.), Handbook of self-regulation: Research, theory, and applications (pp. 369-413). Guilford Press.

Hu, L.-t., \& Bentler, P. M. (1999). Cutoff criteria for fit indexes in covariance structure analysis: Conventional criteria versus new alternatives. Structural Equation Modeling, 6(1), 1-55. https://doi.org/10.1080/10705519909540118.

Jonason, P. K., \& Webster, G. D. (2010). The dirty dozen: A concise measure of the dark triad. Psychological Assessment, 22(2), 420-432. https://doi.org/10.1037/a0019265.

Keller, L., Bieleke, M., \& Gollwitzer, P. M. (2019). Mindset theory of action phases and ifthen planning. In K. Sassenberg, \& M. L. W. Vliek (Eds.), Social psychology in action: Evidence-based interventions from theory to practice (pp. 23-37). Springer.

Keller, L., Gollwitzer, P. M., \& Sheeran, P. (2020). Changing behavior using the model of action phases. In M. S. Hagger, L. Cameron, K. Hamilton, N. Hankonen, \& T. Lintunen (Eds.), The handbook of behavior change. Cambridge University Press.

Kruglanski, A. W., Webster, D. M., \& Klem, A. (1993). Motivated resistance and openness to persuasion in the presence or absence of prior information. Journal of Personality and Social Psychology, 65(5), 861-876. https://doi.org/10.1037/00223514.65.5.861.

Kuhl, J. (1994). Action versus state orientation: Psychometric properties of the Action Control Scale (ACS-90). In J. Kuhl, \& J. Beckmann (Eds.), Volition and personality: Action versus state orientation (pp. 47-59). Hogrefe.

Legrand, E., Bieleke, M., Gollwitzer, P. M., \& Mignon, A. (2017). Nothing will stop me? Flexibly tenacious goal striving with implementation intentions. Motivation Science, 3 (2), 101-118. https://doi.org/10.1037/mot0000050.

Lippke, S., Ziegelmann, J. P., \& Schwarzer, R. (2004). Initiation and maintenance of physical exercise: Stage-specific effects of a planning intervention. Research in Sports Medicine, 12(3), 221-240. https://doi.org/10.1080/15438620490497567. 
Ludwig, R. M., Srivastava, S., \& Berkman, E. T. (2019). Predicting exercise with a personality facet: Planfulness and goal achievement. Psychological Science, 30(10), 1510-1521. https://doi.org/10.1177/0956797619868812.

Luszczynska, A., \& Schwarzer, R. (2003). Planning and self-efficacy in the adoption and maintenance of breast self-examination: A longitudinal study on self-regulatory cognitions. Psychology \& Health, 18(1), 93-108. https://doi.org/10.1080/ 0887044021000019358.

Lynch, J. G., Netemeyer, R. G., Spiller, S. A., \& Zammit, A. (2010). A generalizable scale of propensity to plan: The long and the short of planning for time and for money. Journal of Consumer Research, 37(1), 108-128. https://doi.org/10.1086/649907.

Martiny-Huenger, T., Bieleke, M., Oettingen, G., \& Gollwitzer, P. M. (2016). From thought to automatic action: Strategic and incidental action control by if-then planning. In R. Deutsch, B. Gawronski, \& W. Hofmann (Eds.), Reflective and impulsive determinants of behavior (pp. 69-84). Psychology Press.

McCrae, R. R., \& Costa, J. P. T. (2007). Brief versions of the NEO-PI-3. Journal of Individual Differences, 28(3), 116-128. https://doi.org/10.1027/1614 0001.28.3.116.

McWilliams, L., Bellhouse, S., Yorke, J., Lloyd, K., \& Armitage, C. J. (2019). Beyond "planning": A meta-analysis of implementation intentions to support smoking cessation. Health Psychology, 38(12), 1059-1068. https://doi.org/10.1037/ hea0000768.

Moffitt, T. E., Arseneault, L., Belsky, D., Dickson, N., Hancox, R. J., Harrington, H., ... Caspi, A. (2011). A gradient of childhood self-control predicts health, wealth, and public safety. Proceedings of the National Academy of Sciences of the United States of America, 108(7), 2693-2698. https://doi.org/10.1073/pnas.1010076108.

Mundfrom, D. J., Shaw, D. G., \& Ke, T. L. (2005). Minimum sample size recommendations for conducting factor analyses. International Journal of Testing, 5 (2), 159-168. https://doi.org/10.1207/s15327574ijt0502_4.

Muthén, L. K., \& Muthén, B. O. (1998-2017). Mplus user's guide (8th ed.). Muthén \& Muthén.

Oettingen, G., \& Gollwitzer, P. M. (2010). Strategies of setting and implementing goals. In J. E. Maddux, \& J. P. Tangney (Eds.), Social psychological foundations of clinical psychology (pp. 114-135). Guilford Press.

Patton, J. H., Stanford, M. S., \& Barratt, E. S. (1995). Factor structure of the Barratt impulsiveness scale. Journal of Clinical Psychology, 51(6), 768-774. https://doi.org/ 10.1002/1097-4679(199511)51:6<768::aid-jclp2270510607>3.0.co;2-1.

Peer, E., Vosgerau, J., \& Acquisti, A. (2014). Reputation as a sufficient condition for data quality on Amazon mechanical Turk. Behavior Research Methods, 46(4), 1023-1031. https://doi.org/10.3758/s13428-013-0434-y.

Prenda, K. M., \& Lachman, M. E. (2001). Planning for the future: A life management strategy for increasing control and life satisfaction in adulthood. Psychology and Aging, 16(2), 206-216. https://doi.org/10.1037//0882-7974.16.2.206.

Robins, R. W., Hendin, H. M., \& Trzesniewski, K. H. (2001). Measuring global selfesteem: Construct validation of a single-item measure and the Rosenberg Self-Esteem Scale. Personality and Social Psychology Bulletin, 27(2), 151-161. https://doi.org/ 10.1177/0146167201272002.

Rosenbaum, M. (1980). A schedule for assessing self-control behaviors: Preliminary findings. Behavior Therapy, 11(1), 109-121. https://doi.org/10.1016/S0005-7894 (80)80040-2.

Rosenberg, M. (1965). Society and the adolescent self-image. Princeton University Press.

Runge, J. M., \& Lang, J. W. B. (2019). Can people recognize their implicit thoughts? The motive self-categorization test. Psychological Assessment, 31(7), 939-951. https:// doi.org/10.1037/pas0000720.

Schönbrodt, F. D., \& Perugini, M. (2013). At what sample size do correlations stabilize? Journal of Research in Personality, 47(5), 609-612. https://doi.org/10.1016/j. jrp.2013.05.009.
Schroder, K. E. E., Ollis, C. L., \& Davies, S. (2013). Habitual self-control: A brief measure of persistent goal pursuit. European Journal of Personality, 27(1), 82-95. https://doi. org/10.1002/per.1891.

Sheeran, P., \& Webb, T. L. (2016). The intention-behavior gap. Social and Personality Psychology Compass, 10(9), 503-518. https://doi.org/10.1111/spc3.12265.

Slaney, R. B., Rice, K. G., Mobley, M., Trippi, J., \& Ashby, J. S. (2001). The revised Almost Perfect Scale. Measurement and Evaluation in Consulting and Development, 34 (3), 130-145. https://doi.org/10.1080/07481756.2002.12069030.

Sniehotta, F. F., Schwarzer, R., Scholz, U., \& Schüz, B. (2005). Action planning and coping planning for long-term lifestyle change: Theory and assessment. European Journal of Social Psychology, 35(4), 565-576. https://doi.org/10.1002/ejsp.258.

Soto, C. J., \& John, O. P. (2017). Short and extra-short forms of the Big Five Inventory-2: The BFI-2-S and BFI-2-XS. Journal of Research in Personality, 68, 69-81. https://doi. org/10.1016/j.jrp.2017.02.004.

Strathman, A., Gleicher, F., Boninger, D. S., \& Edwards, C. S. (1994). The consideration of future consequences: Weighing immediate and distant outcomes of behavior. Journal of Personality and Social Psychology, 66(4), 742-752. https://doi.org/ 10.1037/0022-3514.66.4.742.

Tangney, J. P., Baumeister, R. F., \& Boone, A. L. (2004). High self-control predicts good adjustment, less pathology, better grades, and interpersonal success. Journal of Personality, 72(2), 271-324. https://doi.org/10.1111/j.0022-3506.2004.00263.x.

Tuckman, B. W. (1991). The development and concurrent validity of the Procrastination Scale. Educational and Psychological Measurement, 51(2), 473-480. https://doi.org/ 10.1177/0013164491512022.

Verplanken, B., \& Orbell, S. (2003). Reflections on past behavior: A self-report index of habit strength. Journal of Applied Social Psychology, 33(6), 1313-1330. https://doi. org/10.1111/j.1559-1816.2003.tb01951.x.

Webb, T. L., Christian, J., \& Armitage, C. J. (2007). Helping students turn up for class: Does personality moderate the effectiveness of an implementation intention intervention? Learning and Individual Differences, 17(4), 316-327. https://doi.org/ 10.1016/j.lindif.2007.03.001.

Webb, T. L., \& Sheeran, P. (2004). Identifying good opportunities to act: Implementation intentions and cue discrimination. European Journal of Social Psychology, 34(4), 407-419. https://doi.org/10.1002/ejsp.205.

Webb, T. L., \& Sheeran, P. (2007). How do implementation intentions promote goal attainment? A test of component processes. Journal of Experimental Social Psychology, 43(2), 295-302. https://doi.org/10.1016/j.jesp.2006.02.001.

Wieber, F., Thürmer, J. L., \& Gollwitzer, P. M. (2015). Promoting the translation of intentions into action by implementation intentions: Behavioral effects and physiological correlates. Frontiers in Human Neuroscience, 9, 395. https://doi.org/ 10.3389/fnhum.2015.00395.

Wolff, W., Bieleke, M., \& Schüler, J. (2019). Goal striving and endurance performance. In C. Meijen (Ed.), Endurance performance in sport: Psychological theory and interventions (pp. 125-137). Routledge.

Wolff, W., Bieleke, M., Stähler, J., \& Schüler, J. (2020). Too bored for sports? Adaptive and non-adaptive latent personality profiles for exercise behavior. SportRxiv. https://doi.org/ 10.31236/osf.io/tjw89.

Yuriev, A., Dahmen, M., Paillé, P., Boiral, O., \& Guillaumie, L. (2020). Pro-environmental behaviors through the lens of the theory of planned behavior: A scoping review. Resources, Conservation and Recycling, 155, Article 104660. https://doi.org/10.1016/ j.resconrec.2019.104660.

Zimmerman, B. J. (2002). Becoming a self-regulated learner: An overview. Theory Into Practice, 41(2), 64-70. https://doi.org/10.1207/s15430421tip4102_2. 